\title{
The effectiveness of a group psycho-educational program on family caregiver burden of patients with mental disorders
}

\author{
Ali Navidian ${ }^{1 *}$, Fatihe Kermansaravi ${ }^{2}$ and Shahindokht Navabi Rigi ${ }^{3}$
}

\begin{abstract}
Background: Brief family intervention may have a positive impact on family caregivers for patients with mental disorders. We assessed the effectiveness of a group psycho-educational program on family caregivers for patients with schizophrenia and mood disorders.

Methods: This randomized controlled trial was performed on 100 caregivers for patients with mental disorders attending the Isfahan Behavioral Sciences Research Center (IBSRC), in Isfahan, Iran. One hundred family caregivers of patients with schizophrenia $(n=50)$ and mood disorders $(n=50)$ were selected and assigned randomly to either a psycho-educational group intervention or routine care in each diagnosis category. The caregivers were followed for 3 months. Caregiver burden was assessed using the Zarit Burden Interview

Results: The mean scores of the Zarit caregiver burden decreased significantly for the group that participated in the psycho-educational program, while scores in the control group did not change significantly.

Conclusions: This group intervention program was effective to reduce the caregiver burden for both categories of mental disorders in the Iranian population. This group intervention program may improve the quality of life of patients and caregivers by improving the standards of care giving.
\end{abstract}

Trial registration: $\mathrm{RCT}$ registration number: IRCT138804272200N

Keywords: Mental disorders, Caregivers, Education, Iran

\section{Background}

The importance of caregiver burden was pointed out as early as the 1950s [1]. Over the past two decades, the focus of the deinstitutionalization movement has shifted from psychiatric hospitals to community mental health centers. However, enough money has not been allocated towards such resources.

Family members of patients with seriously mental illnesses were encouraged to participate in this study to gain an understanding of practical help and emotional support for these patients [2,3]. They often provide significant services at home to their relatives who need their help; however, lack of sufficient information and resources has always been an obstacle. As a result, they

\footnotetext{
* Correspondence: alinavidian@gmail.com

${ }^{1}$ Department of Mental Health \& Psychiatric Nursing, Pregnancy Health Research Center, Zahedan University of Medical Sciences, Zahedan, Iran Full list of author information is available at the end of the article
}

are not well-prepared to play their roles as efficiently as possible [3-5].

Although care giving may have multiple rewards [6], extensive studies indicate that the intensity and diversity of care giving leads to caregiver strain and burden [7-9]. Family caregivers experience relationship strains, and feelings of grief, loss, sadness, anger, frustration, shame, and guilt as a consequence of caring for a relative at home [10]. Such strains and burden, if left untreated, can result in poor physical and mental health in the family caregivers [11,12]. As a consequence, this burden may reduce the quality of care giving and endanger the mental and physical health of the caregivers themselves [13]. Therefore, interventions such as education, support, psychotherapy, and respite, can be effective in reducing caregiver burden. These interventions enhance the quality of care giving, as well as the physical and mental health of caregivers $[14,15]$. Thus, reducing

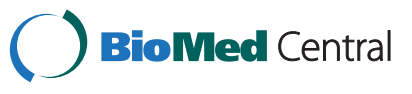


caregiver burdens provides better professional mental health outcomes for patients with mental disorders and their caregivers.

Although numerous studies have been performed over the past three decades, more studies need to enhance the development and evaluation of effective family intervention strategies. Psychiatric services for patients with severe mental illnesses and their families also need to be improved [16,17]. Group education programs have been widely recommended as a valuable strategy to deliver support and information to family caregivers [5].

Several other studies have also demonstrated the efficacy of family psycho-educational interventions in reducing of relapses, re-hospitalization [18-20] and family burden [21-23]. The psycho-educational intervention is a set of systematic interventions based on supportive and cognitive behavior therapy approaches with emphases on patients and family needs. The intervention is focused on increasing patient and family knowledge about mental disorders, adjusting to mental illness, and communicating and facilitating problem solving skills [24].

Iranian families are characterized by their intimate interpersonal relationships and many interactions among family members. Therefore, illness in one family member results in a substantial burden for the whole family. In addition, Iranian families report a low level of formal support services as compared with their Western peers [25]. Currently, there are no community mental health centers which specifically follow up on patients in Iran. The patients mainly are referred to psychiatrists, psychiatric centers, or primary healthcare centers that do not clearly address the specific needs of each family. Moreover, since mental illness is considered as a taboo in Iranian cultural settings, and many families are not aware of the needs and illness of their family members, they experience a great amount of burden. Also, neither the patients nor their families receive routine non pharmaceutical treatments such as family interventions. Finally, there are not trained professionals to perform such interventions in Iran.

Considering the lack of routine long term psychoeducational programs for patients and their families based on their specific needs, we investigated the efficacy of family psycho-education in reducing family caregiver burden.

\section{Methods}

\section{Design}

In a randomized controlled trial (RCT), we evaluated the effectiveness of a weekly, 4-session psycho-educational group intervention for caregivers of patients with mental disorders over a period of three months compared with routine care (control group) in the Isfahan Behavioral
Sciences Research Center, in Isfahan, Iran. This study was done on a sample of family caregivers of patients with schizophrenia $(n=50)$ and mood disorders $(n=50)$. In each group, 25 caregivers were assigned randomly to either a psycho-educational group intervention or routine care.

In our study, a caregiver is defined as a member of the family who has the most frequent contact with the patient, financially supports the patient, has participated in the patient's treatment, is older than 15 years, and has good communicational skills. Family caregiver burden was assessed using the Zarit Burden Interview (ZBI) at baseline, at the end of the intervention period, and three months after the intervention. The results were compared between each group.

\section{Ethical considerations}

Ethical approval was given by the study hospital's ethics committee and the hospital's research governance recommendations were followed. Written informed consent for participation in the study was obtained from family caregivers. An information leaflet about the study was distributed to family caregivers of patients with mental disorders.

This research was approved by the Ethics Committee of Isfahan Medical Sciences and was registered in the Iranian Registry of Clinical Trials (IRCT) with a reference number of IRCT138804272200N1.

\section{Instruments}

Data were collected using the ZBI questionnaire. The ZBI is a widely used 22-item assessment tool for measuring the caregiver's perceived burden in providing family care. The questionnaire was translated, and modified according to Iranian cultural standards. Its reliability was calculated using the test-retest method $(\mathrm{r}=0.94)$.

The psychometric properties of the ZBI include an acceptable inter-item reliability and convergent validity, indicated by a Cronbach's alpha of 0.79 and a correlation coefficient of 0.71 between the caregiver's global evaluation and ZBI scores (Scott, Roberto, Hutton, \& Slack, 1985). A test-retest reliability of 0.71 and internal consistency (Cronbach's alpha $=0.91$ ) have also been reported (26-28).

This questionnaire asks family caregivers questions about physical, psychological, economic, and communication problems that cause stress and strain for caregivers. The items are answered on a five-point scale ranging from 0 (never) to 4 (always). Scores were calculated by summing up the total chosen statement which ranges from 0 to 88 , that higher scores implying greater perceived caregiver burden. 


\section{Intervention}

We developed our intervention based on the families' needs in schizophrenia and mood disorder groups and the existing literature $(29,30)$. The psycho-educational program consisted of four 120-min sessions held during four consecutive weeks with one session each week. Six psycho-educational groups of eight or nine caregivers (three groups for schizophrenia and three groups for mood disorders) were arranged with the same content, and the program was conducted by a mental health nurse or psychiatrist.

The goals and content of each of the four sessions are summarized in Table 1. At the beginning of the first session, a needs assessment was performed in which we asked the caregivers about the types of issues and problems they have with their patients, and what they would like to know about their patient's condition so that we could organize the interventions appropriately. After evaluating the subjects' needs assessments, each psycho-educational session included a variety of educational techniques designed to enhance the participant's learning and maintain their attention (for example; visual aids such as charts, film presentations and Microsoft PowerPoint slideshows).

The first part of each session consisted of a lecture given by a psychiatrist or mental health nurse, and the last part of each session (50 min) consisted of a question-and-answer and group discussion period. During this period, the caregivers described situations and incidents related to their family members and discussed alternative ways of coping with and resolving their difficulties with care giving. During these sessions, the caregivers were informed about the patients' disorder patterns, and psychosocial issues were discussed. Moreover, the caregivers were taught how to care for themselves, monitor their own feelings, and how to manage symptoms efficiently. Coping skills and problem solving strategies were also taught in a group format to be the most effective.

\section{Statistical analysis}

The SPSS v. 15 was used for statistical analyses. At baseline, socio-demographic characteristics of the two groups were compared using the chi-square test. Between-group comparisons of the variables were performed with Student's $t$-tests, and repeated measurement analyses of variance were used to determine whether the improvements in these variables changed over time.

\section{Results}

The mean age of the caregivers was $43.03 \pm 11.90$ years. Of these caregivers, $47 \%$ were the patients' parents, $22 \%$ were the spouses, $20 \%$ were the siblings, and $11 \%$ were the children. The majority of the participants
(92\%) were married, and 56\% were housewives. The patients' mean age was $34 \pm 13.14$ years, and most of them (58\%) were male. Table 2 summarizes the patients' and their caregivers' additional socio-demographic and clinical data.

Comparisons of the baseline scores of the variables (FCB Score for Schizophrenia and FCB Score for Mood disorders) did not detect any significant differences between the two groups. The findings after completion of the psycho-educational program and the three month post-intervention scores indicated statistically significant reductions in the family burden scores as compared with the baseline scores (Table 3).

These results regarding the family caregivers to patients with mood disorders showed that the mean scores of burden in the control group was 49.04, 55.76, and 52.88 at baseline, after intervention, and 3 months after intervention, respectively. The mean scores in the experimental group were 52.48, 25.44, and 29.44, respectively. These results are statistically significantly different for the mean burden scores of caregivers for patients with mental disorders between the experimental and control groups $(\mathrm{P}=0.001, \mathrm{~F}=71.99)$.

Moreover, the interaction between group members and the level of burden for the three stages measured was also significant $(\mathrm{P}=0.001, \mathrm{~F}=61.23)$, or, in other words, the decrease of burden in the experimental group is significant compared with the control group. These data demonstrate that group interaction reduced caregiver burden in the experimental group, with the mean burden score being reduced considerably from 52.48 before the intervention to 25.44 after the intervention. This decrease remained low three months after intervention. The mean scores at time 0 (baseline) and time 2 (three month post-intervention) indicated that the experimental group had improved steadily in the family caregivers' burden of schizophrenia $(\mathrm{P}<0.001)$.

For family caregivers of schizophrenic patients, the mean burden score in the control group was 57.40, 47.08, and 44.52 at baseline, after intervention, and three months after the intervention, respectively (Table 3), compared with the mean burden scores of 57.28, 32.12, and 35.80, respectively, in the experimental group. Variance analysis with repeated measures demonstrated a significant difference in the mean burden score between the two groups $(\mathrm{P}=0.002, \mathrm{~F}=11.32)$, with the mean burden score in the experimental group being lower than the control group. Also, there is a significant correlation between group interaction and the level of burden for the three stages of measurement $(P=0.001, F=20.68)$. In other words, the burden in the experimental group decreased significantly as compared with the control group. Intervention had a positive effect on reducing caregiver burden in such a way that the mean burden 
Table 1 The contents of the psycho-educational program

\begin{tabular}{|c|c|c|}
\hline Session & Session goal & Content \\
\hline \multirow[t]{4}{*}{ Pre Session } & \multirow{4}{*}{$\begin{array}{l}\text { To orient caregivers to the program, to create a } \\
\text { trusting relationship between the caregivers } \\
\text { and instructors }\end{array}$} & $\begin{array}{l}\text { - Overview of the program and introduction of the instructors and members } \\
\text { to each other. }\end{array}$ \\
\hline & & $\begin{array}{l}\text { - Discussion of the importance of orientation to patient behaviors } \\
\text { and symptoms }\end{array}$ \\
\hline & & - Completion of Zarit Burden Interview (ZBI) questionnaire by participants. \\
\hline & & - Assessment of family needs. \\
\hline \multirow[t]{3}{*}{1} & \multirow[t]{3}{*}{$\begin{array}{l}\text { To understand the disorder, its symptoms and } \\
\text { treatments, and its effects on patients and families }\end{array}$} & $\begin{array}{l}\text { - Case presentation. The instructor offers explanations of the symptoms } \\
\text { and behaviors, and their effects on the family. }\end{array}$ \\
\hline & & - Discussion of the etiology and treatments \\
\hline & & - Question-answer and group discussion. \\
\hline \multirow[t]{6}{*}{2} & \multirow{6}{*}{$\begin{array}{l}\text { To recognize the effect of medications and compliance, } \\
\text { and to orient caregivers to the warning signs of relapse } \\
\text { and relapse prevention }\end{array}$} & - A review of the previous session. \\
\hline & & $\begin{array}{l}\text { - Discussion of positive and negative effects of drugs and problems } \\
\text { related to side effects. }\end{array}$ \\
\hline & & - Emphasis on the importance of drug compliance. \\
\hline & & - Discussion about the warning signs of relapse. \\
\hline & & - Explanation of the family role in relapse prevention. \\
\hline & & - Question-answer and group discussion. \\
\hline \multirow[t]{7}{*}{3} & \multirow{7}{*}{$\begin{array}{l}\text { To manage the patient's symptoms, to gain skills in } \\
\text { coping with the patient's symptoms, and to understand } \\
\text { effective ways to express emotion and improve } \\
\text { communication skills. }\end{array}$} & - A review of the previous session. \\
\hline & & $\begin{array}{l}\text { - Discussion of the importance of effective communication skills in the } \\
\text { family and with the patients when they have symptoms. }\end{array}$ \\
\hline & & $\begin{array}{l}\text { - Explanation of skills for coping with some of the patients' symptoms, } \\
\text { and cognitive and behavioral techniques for managing patients' symptoms }\end{array}$ \\
\hline & & - Exploring intense emotions towards the patient. \\
\hline & & $\begin{array}{l}\text { - Discussion of expressing emotion and the emotional environment } \\
\text { in the family. }\end{array}$ \\
\hline & & $\begin{array}{l}\text { - Discussion of how to cope with the patient's negative emotions } \\
\text { (for example, suicide behavior in mood disorder patients). }\end{array}$ \\
\hline & & - Question-answer and group discussion. \\
\hline \multirow[t]{6}{*}{4} & \multirow{6}{*}{$\begin{array}{l}\text { To orient caregivers to stress management and } \\
\text { relaxation for the family }\end{array}$} & - A review of the previous session. \\
\hline & & - Introduction of the importance of stress management in the family. \\
\hline & & - Discussion of ways to reduce stress. \\
\hline & & - Practicing relaxation methods during the session. \\
\hline & & - Question-answer and group discussion. \\
\hline & & - Conclusion \\
\hline
\end{tabular}

score decreased considerably from 57.28 at baseline to 32.12 after intervention and still remained low three months after intervention. The mean scores at time 0 (baseline) and time 2 (three month post-intervention) indicated that the experimental group improved steadily in the family caregivers' burden of mood disorders $(\mathrm{P}<0.001)$.

\section{Discussion}

Most caregivers in our study were women who also were housewives. In Iranian households, girls or women are responsible for taking care of children, patients, elderly, and disabled people in the family as a part of their daily household chores [13]. Studies in western countries also have shown that women and girls were usually the main caregivers at home with most women being under 60 years of age. The primary caregivers for the elderly are usually their daughters or wives $[27,28]$.

Burden is one of the most commonly used measures to evaluate the effect of intervention. The results of our study confirmed the hypothesis that psycho-educational family intervention has a significant effect on reducing the family caregiver burden when provided in a routine manner [32] for caregivers of family members with schizophrenia and mood disorders. A prospective study on the relationship between burden and coping in caregivers for patients with schizophrenia and mood disorders [33] showed that these caregivers face similar levels 
Table 2 Clinical and socio-demographic data of the patients and their caregivers

\begin{tabular}{|c|c|c|c|}
\hline \multicolumn{2}{|c|}{ Demographic and clinical features } & \multirow{2}{*}{$\begin{array}{c}\begin{array}{c}\text { Percentage } \\
\text { of patients }\end{array} \\
58\end{array}$} & \multirow{2}{*}{$\begin{array}{c}\begin{array}{c}\text { Percentage } \\
\text { of caregivers }\end{array} \\
30\end{array}$} \\
\hline Sex & Male & & \\
\hline & Female & 42 & 70 \\
\hline \multirow[t]{3}{*}{ Age } & $<20$ years & 13 & 2 \\
\hline & $21-35$ years & 48 & 28 \\
\hline & 36 years & 39 & 70 \\
\hline \multirow[t]{2}{*}{ Marital status } & Married & 65 & 92 \\
\hline & Single & 35 & 8 \\
\hline \multirow{3}{*}{$\begin{array}{l}\text { Educational } \\
\text { background }\end{array}$} & No studies/illiterate & 3 & 0 \\
\hline & Primary education & 48 & 58 \\
\hline & $\begin{array}{l}\text { Higher education } \\
\text { or more }\end{array}$ & 49 & 42 \\
\hline \multirow{5}{*}{$\begin{array}{l}\text { Occupational } \\
\text { status }\end{array}$} & Housekeeper & 30 & 56 \\
\hline & Employee & 11 & 13 \\
\hline & Unemployed & 30 & 6 \\
\hline & $\begin{array}{l}\text { Business \& similar } \\
\text { jobs }\end{array}$ & 24 & 19 \\
\hline & Other & 5 & 6 \\
\hline \multirow[t]{2}{*}{ Diagnosis } & Schizophrenia & 50 & - \\
\hline & Mood disorders & 50 & - \\
\hline
\end{tabular}

of burden and use similar types of coping methods to deal with it. Another psycho-educational group intervention for relatives of patients with bipolar disorders showed that the relative's insight about the disease improved and their burden reduced after one year of follow-up [34].
Magliano and colleagues (2006) reported that $40 \%$ of their patients and $45 \%$ of their relatives had a significant improvement in their social interactions during the intervention period. Other RCTs that were performed on Chinese [35] and Indian [36] family caregivers for patients with mental disorders confirmed that scores significantly improved after structured psychoeducational interventions compared with routine outpatient care.

We have demonstrated that intervention specifically developed for caregivers for patients with schizophrenia and mood disorder in Iran positively can influence burden. Compared with previous studies in which intervention was designed and performed for only a specific group of family caregivers [14,34-36], the intervention used in our study was designed to be effective for care givers for patients with schizophrenia and mood disorders, who comprise considerable numbers of the hospital inpatients in Iranian psychiatric wards.

\section{Limitations of this study}

The current study has some limitations. Each family caregiver's personal experience and perception of care could have differed considerably in the experimental and control groups because of personal, familial, and economical differences. The sample size was relatively small, so larger studies are needed to confirm these results. The improvements in the family caregivers' burden were confirmed for a relatively short follow-up period of three months, compared to other studies with a follow-up duration of one year [37]. Therefore, further studies are needed to confirm the long-term effects of this family

Table 3 Family caregiver burden at Time 0 (baseline), time 1 (post-intervention) and time 3(three months post-intervention)

\begin{tabular}{|c|c|c|c|c|}
\hline Variables & $\begin{array}{c}\text { Experimental group } \\
(n=25) \\
\text { Mean } \pm \text { SD }\end{array}$ & $\begin{array}{l}\text { Control group } \\
\qquad(n=25) \\
\text { Mean } \pm \text { SD }\end{array}$ & & $P$ value \\
\hline \multicolumn{5}{|l|}{ FCB Score for Schizophrenia } \\
\hline Time 0 & $57.28 \pm 10.60$ & $57.40 \pm 11.59$ & & $>0.05$ \\
\hline Time 1 & $32.12 \pm 8.52$ & $47.08 \pm 10.33$ & & $0.001^{*}$ \\
\hline Time 2 & $35.80 \pm 7.48$ & $44.52 \pm 8.28$ & & $0.003^{*}$ \\
\hline Effect of time & & & 14.10 & $0.01^{*}$ \\
\hline Effect of treatment & & & 11.32 & $0.002^{*}$ \\
\hline Interaction of time and treatment & & & 20.68 & $0.001^{*}$ \\
\hline \multicolumn{5}{|l|}{ FCB Score for Mood disorders } \\
\hline Time 0 & $52.48 \pm 9.02$ & $49.04 \pm 11.07$ & & $>0.05$ \\
\hline Time 1 & $25.44 \pm 6.81$ & $55.76 \pm 11.77$ & & $0.0001^{*}$ \\
\hline Time 2 & $29.44 \pm 7.29$ & $52.88 \pm 10.50$ & & $0.0001^{*}$ \\
\hline Effect of time & & & 48.07 & $0.001^{*}$ \\
\hline Effect of treatment & & & 71.99 & $0.001^{*}$ \\
\hline Interaction of time and treatment & & & 61.23 & $0.001^{*}$ \\
\hline
\end{tabular}


psycho-educational intervention. Also more studies are recommended to apply different psycho-educational models, and family to family interventions, etc.

\section{Conclusions}

Our group psycho-educational intervention improves the family caregiver burden. Our findings provide evidence that psycho-educational group intervention can be an effective family intervention for Iranian caregivers for family members with mood disorders and schizophrenia. Based on our findings, psycho-educational services for patients and their caregivers are helpful, beneficial and effective. The psycho-educational intervention used in our study is simple, feasible, and cheap, and could prevent the recurrence of severe mental disorders and long hospital admissions, without increasing mental burden or reducing the satisfaction of family care givers.

As intervention was effective in decreasing the burden of family caregivers for patients with schizophrenia and mood disorders, it is also likely that this program will be applicable to other psychiatric disorders. Future investigations should focus on obtaining more precise estimates of the contributions of the specific components of this program in reducing burden. The knowledge of how to support family caregivers for persons with mental disorders should be included in the education of healthcare professionals in general, and for the psychiatric team, in particular.

\section{Abbreviations}

FCB: Family Caregiver Burden; IBSRC: Isfahan Behavioral Sciences Research Center; RCT: Randomized Controlled Trial; SD: Standard Deviation; ZBI: Zarit Burden Interview.

\section{Competing interest}

The authors declare that they have no competing interests.

\section{Author Contributions}

AN: Main investigator, creating the research question and research design, supervising the study, drafting the article and the guarantor.FK: Data analysis and critical revision of the article. SNR: managing group sessions. All authors read and approved the final manuscript.

\section{Acknowledgements}

We would like to thank the psychiatrist and the mental health nurse who managed the group intervention sessions for the caregivers and the patients who participated in our study. We would also like to thank the Isfahan Behavioral Sciences Research Center that provided the research grant for this study. Participants' informed consent was obtained before recruitment, and written consent for publication was obtained from the patient's relative.

\section{Author details}

${ }^{1}$ Department of Mental Health \& Psychiatric Nursing, Pregnancy Health Research Center, Zahedan University of Medical Sciences, Zahedan, Iran. ${ }^{2}$ Department of Nursing, Pregnancy Health Research Center, Zahedan University of Medical Sciences, Zahedan, Iran. ${ }^{3}$ Department of Midwifery, Pregnancy Health Research Center, Zahedan University of Medical Sciences, Zahedan, Iran
Received: 6 March 2012 Accepted: 13 July 2012

Published: 1 August 2012

\section{References}

1. Honea NJ, Brintnall RA, Given B, Sherwood P, Colao DB, Somers SC, Northouse LL: Putting Evidence Into Practice: Nursing Assessment and Interventions to Reduce Family caregiver Strain and Burden. Clin J Oncology Nur 2008, 12(3):507-516.

2. Gutierrez-Maldonado J, Caqueo-Urizar A, Kavanagh D: Burden of Care and General Health in Families of Patients with Schizophrenia. So Psych and Psychiatry Epi 2005, 40(11):899-904.

3. Caqueo-Urizar A: Gutierrez- Maldonado J: Burden of Care in Families of Patients with Schizophrenia. Qual Life Res 2006, 15:719-724.

4. Corsentino EA, Molinari V, Gum AM, Roscoe LA, Mills WL: Family Caregivers' Future Planning for Younger and Older Adults with Serious Mental IIIness. J of App Gerontol 2008, 27(4):466-471.

5. Hudson P, Quinn K, Kristjanson L, Thomas T, Braithwaite M, Fisher J, Cockayne M: Evaluation of A Psycho-educational Group Program for Family Caregivers in Home-Based Palliative Care. Palliative Med 2008, 22 (2):70-80.

6. Picot SJ: Family Caregivers: Windows into Their Worlds. Reflections 1996, 22(4):13-14.

7. Vitaliano PP, Katon WJ: Effects of stress on family caregivers: Recognition and Management. Psych Times 2006, 23(7):24-31.

8. Onega LL: Helping Those Who Help Others. Am J of Nur 2008, 108(9):62-64.

9. Grandon P, Jenaro C, Lemos S: Primary Caregivers of Schizophrenia Outpatients: Burden and Predictor Variables. Psychiatry Res 2007, 185 (3):335-343.

10. Kristjanson L, Aoun S: Palliative Care for Families: Remembering the hidden patients. Canad J Psychiatry 2004, 49:359-365.

11. Goode KT, Haley WE, Roth DL, Fotd GR: Predicting Longitudinal Changes in caregiver Physical and Mental Health: A Stress Process Model. Health Psycho 1998, 17(2):190-198.

12. Karanci AN: Caregivers of Turkish schizophrenic patients: Causal attributions, burdens and attitudes to help from the health professional. Soc Psychiatry Psychiatr Epidemiol 2004, 30(6):261-268.

13. Navidian A, Bahari F: Burden Experienced by Family Caregivers of Patients with Mental Disorders. Pakis J Psychol Res 2008, 23(1-2):19-28.

14. Gutierrez-Maldonado J, Caqueo-Urizar A: Effectiveness of A Psychoeducational Intervention for Reducing Burden in Latin American Families of Patients with Schizophrenia. Qual Life Res 2007, 16(5):739-747.

15. Riebscheger J, Scheid C, Luz C, Mickus M, Liszewski C, Eaton M: How are the Experiences and Needs of Families of Individuals with mental Illness Reflected in Medical Education Guidelines? Acad Psychiatry 2008, 32 (2):119-126.

16. Awad AG, Voruqanti LN: The Burden of Schizophrenia of Caregivers: A Review. Pharmacoeconomics 2008, 26(2):149-162.

17. Sorensen S, Pinquart M, Duberstein P: How Effective are Interventions with Caregivers? An Update Meta Analysis. Gerontologist 2002, 42(3):356-372.

18. Mueser KT, Sengupta A, Schooler NR, et al: Family treatment and medication dosage reduction in schizophrenia: effects on patient social functioning, family attitudes, and burden. J Consult Clin Psychol 2001, 69:3-12.

19. McFarlane WR, Dixon L, Lukens E, et al: Family psycho education and schizophrenia: a review of the literature. J Marital Fam Ther 2003, 29:223-245.

20. Falloon IRH: Family interventions for mental disorders: efficacy and effectiveness. World Psychiatry 2003, 2:20-28.

21. Stam H, Cuijpers P: Effects of family interventions on burden of relatives of psychiatric patients in the Netherlands: a pilot study. Community Ment HealthJ 2001, 37:179-187.

22. Berglund N, Vahlne JO, Edman A: Family intervention in schizophrenia: impact on family burden and attitude. Soc Psychiatr Psychiatr Epidemiol 2003, 38:116-121.

23. Bauml J, Frobose T, Kraemer S, Rentrop M, Pitschel-Walz G: A basic psychotherapeutic intervention for patients with Schizophrenia and their families. Schizophr Bull 2006, 32:51-59.

24. Hazel NA, McDonell MG, Short RA: Impact of multiple-family groups for outpatients with schizophrenia on caregivers' distress and resources. Psychiatr Serv 2004, 55:35-41. 
25. Zoladl M, Sharif F, Kazemnejad A: Shared experiences of families with a mentally ill member. Tehran: Tarbiat Modaress University; 2009.

26. Zarit SH, Todd PA, Zarit JM: Subjective burden of husbands and wives as caregivers: a longitudinal study. Gerontologist 1986, 26:260-266.

27. Smith A, Schwirian PM: The relationship between caregiver burden and TBI survivor's cognition and functional ability after discharge. Reh Nur 1998, 4(2):252-257.

28. Lopelowicz A, Zarit R, Smith VG, Mintz J, Liberman RP: Disease management in Latinos with schizophrenia: A Family - Assisted Skills training approach. Schizophr Bull 2003, 29(2):211.

29. Anderson CM, Reiss DJ, Hogarty GE: Schiziphrenia and Family: A practioner's Guide to psychoeducation and management. New York: Guilford Press.

30. Stengard E: Educational intervention for the relatives of schizophrenia patients in Finland. Nord J Psychiatr 2003, 57:271-277.

31. Acton GJ, Kang J: Intervention to reduce the burden of caregiving for an adult with dementia: a meta-analysis. Res Nurs Health 2002, 24:349-360.

32. Magliano L, Fiorillo A, Magliano C, De Rosa C, Favata G, Sasso A, Prezioso M, et al: Family Psycho-educational Interventions for Schizophrenia in Routine Setting: Impact of Patients' Clinical Status and Social Functioning and on relatives' Burden and Resources. Epidemiol Psychiatry 2006, 15(3):219-227.

33. Chadd RK, Singh TB, Ganguly KK: A Prospective Study of Relationship Between Burden and Coping in Caregivers of Patients with Schizophrenia and Bipolar Affective Disorder. Soc Psychiatry Psychiatr Epidemiol 2007, 42(11):22-30

34. Bernhard B, Schaub A, Kummler P, Dittmann S, Severus E, Seemuller F, Born C, Forsthoff A, Licht RW, Grunze H: Impact of Cognitive-

Psychoeducational Interventions in Bipolar patients and their Relatives. Eur Psychiatry 2006, 21:81-86.

35. Chien WT, Thompson DR, Norman I: Evaluation of A Peer- Led Mutual Support Group for Chinese Families of People with Schizophrenia. Am J Community Psychol 2008, 42(1-2):122-135.

36. Signe A, Solve E: Intervention for family caregivers of people with dementia reduces caregiver burden: development and effect after 6 and 12 months. Scand J Caring Sci 2008, 22:98-109.

37. Karanci AN: Caregivers of Turkish schizophrenic patients: Causal attributions, burdens and attitudes to help from the health professional. Soc Psychiatry Psychiatr Epidemiol 2004, 30(6):261-268.

doi:10.1186/1756-0500-5-399

Cite this article as: Navidian et al: The effectiveness of a group psychoeducational program on family caregiver burden of patients with mental disorders. BMC Research Notes 2012 5:399.

\section{Submit your next manuscript to BioMed Central and take full advantage of:}

- Convenient online submission

- Thorough peer review

- No space constraints or color figure charges

- Immediate publication on acceptance

- Inclusion in PubMed, CAS, Scopus and Google Scholar

- Research which is freely available for redistribution

Submit your manuscript at www.biomedcentral.com/submit
Biomed Central 